\title{
The barriers and challenges toward addressing the social and cultural factors influencing diabetes self-management in Indian populations
}

\author{
Saurav Basu, Suneela Garg
}

Department of Community Medicine, Maulana Azad Medical College, New Delhi, India

\begin{abstract}
Patient adherence to recommended diabetes self-care practices reduces the risk of diabetic complications. However, most clinic-based approaches have proved inadequate in maintaining optimal diabetic self-management and the prevention of undesirable health outcomes at the population level among disadvantaged populations. Several sociocultural factors influence patient adherence to diabetic self-care practices which should be recognized and addressed by the health-care provider, especially in lower socioeconomic status and women patients. The lack of physician empathy and tendency to assign blame upon diabetic patients for the failure of adherence without recognizing the complex sociocultural factors influencing patient behavior can undermine the possibilities for better management. The enlistment of familial support when available is valuable for improving medical adherence and health outcomes in vulnerable diabetic patients with low health literacy. Young unmarried women with diabetes are particularly at risk of diabetes stigma eroding familial support and marital prospects require need effective health communication along with their family. Moreover, women with diabetes have a greater likelihood of compromising their dietary needs for the sake of their familial dietary preferences. The inability of patients to comply with recommended exercise regimen may be derived from environmental factors; primarily unsafe neighborhoods, lack of availability of nearby recreational facilities such as public parks, and cultural resistance in patriarchal social environments. Policy approaches for improving diabetes management in disadvantaged diabetic populations should consider mandatory registration, assured diabetic medication, and follow-up in case of missed appointments. Community mobilization for overcoming societal stigma against women with diabetes also persists as a formidable challenge.
\end{abstract}

Keywords: Adherence, diabetes, gender, India, social

Address for correspondence: Dr. Saurav Basu, Department of Community Medicine, Maulana Azad Medical College, New Delhi, India.

E-mail: saurav.basu1983@gmail.com

Received: 05.01.2017, Accepted: 09.03.2017

\section{INTRODUCTION}

Diabetes mellitus (DM) afflicts an estimated 65 million people in India which is project to exceed 109 million by 2035. ${ }^{[1]}$ Poor metabolic control in DM patients increases

\begin{tabular}{|l|l|}
\hline \multicolumn{2}{|c|}{ Access this article online } \\
\hline Quick Response Code: & Website: \\
\hline & www.joshd.net \\
\cline { 2 - 2 } & $\begin{array}{l}\text { DOI: } \\
\text { 10.4103/joshd.J_Soc_Health_ } \\
\text { Diabetes_3_17 }\end{array}$ \\
\hline
\end{tabular}

their risk of the development of several microvascular and macrovascular complications which affect organs such as eyes, heart, kidneys, pancreas, and nerves ${ }^{[2]}$ and decrease their quality of life, increase health-care costs,

This is an open access article distributed under the terms of the Creative Commons Attribution-NonCommercial-ShareAlike 3.0 License, which allows others to remix, tweak, and build upon the work non-commercially, as long as the author is credited and the new creations are licensed under the identical terms.

For reprints contact: reprints@medknow.com

How to cite this article: Basu S, Garg S. The barriers and challenges toward addressing the social and cultural factors influencing diabetes self-management in Indian populations. J Soc Health Diabetes 2017;5:71-6. 
and may cause premature mortality. ${ }^{[3,4]}$ The adherence to recommended self-care behaviors by DM patients prevents or delays the onset of diabetic complications. ${ }^{[5,6]}$

The American Association of Diabetes Educators has enumerated the following 7 self-care behaviors for successful and effective diabetes self-management: (1) healthy eating, (2) being active, (3) monitoring, (4) taking medications, (5) problem solving, (6) healthy coping, and (7) reducing risks. ${ }^{[7]}$ Self-management behaviors such as blood glucose monitoring and adherence to diabetic medications improve glycemic control while others such as regular intake of green vegetables and exercise are also protective against heart disease. ${ }^{[8,9]}$ However, research from developed nations suggests that clinical interventions through drug therapy and behavioral modifications might be inadequate for preventing undesirable health outcomes, especially among lower socioeconomic status (SES) patients and particularly when evaluated at the population level. ${ }^{[10-13]}$ Unfortunately, in the absence of electronic health records and databases, the evidence toward determining the effect of clinical intervention focused on self-management on long-term health outcomes at the population level among DM patients is lacking in lower income developing nations including India. Therefore, insights into the barriers and challenges which stem from the societal inequity and health disparities should be understood, especially in those health-care settings where they have been hitherto neglected to enhance diabetes management and control both at the individual and population level.

\section{IMPACT OF SOCIAL DETERMINANTS ON SELF-MANAGEMENT BEHAVIOR IN DIABETES MELLITUS PATIENTS}

The social determinants of health have been defined by the World Health Organization (WHO) as "the conditions in which people are born, grow, work, live, and age, and the wider set of forces and systems shaping the conditions of daily life." ${ }^{[14]}$ The development and progression of DM are known to be influenced by the social, economic, and physical environments of the patient. ${ }^{[15-18]}$ The social and cultural factors which influence diabetes self-management of patients in Indian health-care settings are described below:

\section{Low income and social gradient}

Low SES is the most important social determinant of health which impacts medical adherence and health outcomes of diabetic patients since most other social determinants such as education, housing, and food insecurity tend to cluster around it.
Poor medication adherence is a major public health problem globally. ${ }^{[19]}$ There are multiple sociodemographic factors influencing medication adherence in patients suffering from chronic disorders. ${ }^{[19,20]}$ Of them, poor SES has been reported to be a major predictor of poor medication adherence among surveys in Indian diabetic populations. ${ }^{[21-23]}$ The WHO estimates suggest that almost $58 \%$ of the Indian population depend on out-of-pocket expenditure for satisfying their health-care needs with only one-fourth of the population having access to some form of health insurance. ${ }^{[24,25]}$ Most of the Indian population without health-care insurance reside in the informal sector of the economy belonging to the lower social gradient earning minimal wages. Daily wagers often lose wages while attending clinics at government health facilities which dispense free of cost medication. An economic evaluation review by Yesudian et al. found that diabetes drug expenditure was significant, representing more than $50 \%$ of total direct costs among Indian diabetic households. ${ }^{[2]}$ The inability to replenish exhausted drug stocks due to economic constraints has also been reported in surveys among low SES patients even in states with otherwise high per capita income. ${ }^{[21,22]}$

Furthermore, comorbidities are frequently found among diabetics, ${ }^{[27]}$ and difficulty in access to diabetic medication may precipitate decline in medication adherence for their other significant health conditions such as hypertension and hypercholesterolemia. The escalation of out-of-pocket health-care costs due to diabetic complications also worsens poverty and perpetuates health inequity.

\section{Unemployment}

The likelihood of loss of employment due to poor health resulting from diabetic complications is especially greater in those employed in the informal sector lacking effective job security. Decrease in family income could affect out-of-pocket expenditure on diabetes-related health care within the family. Factors such as loss of family support and diabetes-related stigma are known to worsen health outcomes ${ }^{[28,29]}$ and could be accentuated under such situations.

\section{Low education status}

Low education status has been reported to be associated with poor knowledge of diabetes self-care practices. ${ }^{[30,31]}$ In the absence of effective knowledge of diabetes self-care, there is a loss in patient self-efficacy or the confidence of the patient in his or her own ability to adhere to recommended diabetic self-care practices ${ }^{[32]}$ which may reduce patient adherence to treatment recommendation and impair their glycemic control. ${ }^{[33]}$ Diabetic patients 
lacking functional literacy skills are likely to manifest poor health literacy which is their ability to comprehend and adhere to treatment instructions regarding their health. ${ }^{\text {[4-36] }}$

Moreover, poor health literacy is associated with poor knowledge of critical diabetic events such as hypoglycemic symptoms and its self-management. ${ }^{[37]}$ Patients with low health literacy are likely to experience difficulty with reading their medical prescriptions or accurately comprehend complex drug regimens, especially those containing insulin or with high pill load. ${ }^{[38]}$ Similarly, they are unlikely to be able to take advantage of tools such as the diabetic exchange lists which help patients improve adherence to the diabetic diet. ${ }^{[39]}$

The struggle of type 1 diabetics coping with the double burden of low SES and stress of insulin-based diabetes management from a very young age may often reflect in their diminished educational attainments which disadvantages them by restricting their economic and employment opportunities available during their lifetime.

\section{Food insecurity}

Food insecurity is considered as the inability to afford or get access to food essential for a balanced and healthy diet and its replacement with inferior food abundant in saturated fat, salt, or sugar. In the poorer regions of the developing world, diabetic patients below the poverty line may be unable to meet sustenance levels of regular nutrition and may skip their meals. Even patients with a moderately low SES report often report difficulty in adhering to the recommended diabetic nutrition when subject to a rapid inflationary economy. ${ }^{[2]}$

\section{Health-care system factors}

The diabetes patient is expected to receive support from a multidisciplinary group of professionals including diabetes physician, diabetes nurse specialist, educator, dietician, family care doctor, ophthalmologist, oral health specialist, psychologist, podiatrist, and occasionally other specialists such as nephrologist and cardiologist. ${ }^{[40]}$ Major elements of the Indian health-care system, especially those in the periphery, are unable to provide regular specialist care for diabetic patients which is accessible and affordable.

\section{Sociocultural factors}

Diabetes self-management is known to be influenced by the familial environment, especially aspects such as meal preparation. Diabetic patients with lower educational attainment and consequent poor health literacy often require enhanced health-care provider and familial support to maintain adherence to recommended treatment. Family support can reliably improve certain diabetic self-management behaviors such as improvement of medication adherence through reminders, ${ }^{[21]}$ help with application of insulin, promotion of healthy dietary regimen, and regular blood glucose testing. ${ }^{[4]}$ Familial support can help diabetics who experience depression and ameliorate symptoms, ${ }^{[42]}$ but due to the existence of a bidirectional relationship, depression in diabetics may also reduce family support. ${ }^{[43]}$

The extent of familial support received by the diabetic patient is determined by several other variables including employment status of both patient and rest of family and patient relationship with other family members. In the Indian context, where living in a joint and three generation families is still ubiquitous, family support in chronic disorders is explained by the complex interrelationship among several family members. Furthermore, the presence of family does not necessarily translate into support but may occasionally also undermine diabetes control. This is particularly significant from a gender perspective. ${ }^{[4]}$ Young unmarried women diagnosed with diabetes often experience stigma and their families experience struggle with arranging marriages. ${ }^{[4]}$ Women living in certain patriarchal households and cultures may be prevented from venturing out of their homes which preclude the possibility of regular exercise which is essential for the management of diabetes. Women compromising with their diabetic and hypertensive dietary requirements to satisfy familial dietary choices and traditions are also not uncommon. ${ }^{[22]}$

Neighborhoods and transport

Patient neighborhoods often determine the ability of the diabetic patient to achieve optimal diabetes self-management. The availability of adequate parks and recreational facilities is known to enhance physical activity among diabetics, especially those belonging to lower SES. ${ }^{[5,46]}$ In Indian cities at urban slums, resettlement colonies, and even lower middle-class residential colonies, such facilities are often lacking due to the unplanned urban landscapes and encroachments.

The lack of effective transportation is a major barrier to health-care access in chronic disease. ${ }^{[4]}$ Irregular and inefficiently operational public transport in the developing world can discourage poor diabetic patients from traveling to health-care facilities with specialist care which are often located at considerable distances from their residence and workplaces.

CLINICAL ASSESSMENT OF SOCIAL DETERMINANTS FOR BETTER DIABETES MANAGEMENT

Clinicians while focusing on the three pillars of diabetes management - medication, healthy diet, and exercise 
should not overlook the crucial sociocultural factors which represent significant barriers and challenges in attainment of good medical adherence in their patient. Cultural factors influencing the diabetes self-management are often concealed and should be revealed by the diabetic health-care provider by asking several probe questions. Clinicians treating diabetic patient from vulnerable populations in government health facilities should consider the following recommendations for improving health outcomes.

At onset of treatment, the clinician should make a rapid assessment of several social and cultural determinants influencing adherence to treatment, especially employment status (employed/unemployed), availability of any form of health insurance, financial ability to pay for medications in case of disruption of free government supply of required medications for control of diabetes, and any associated comorbidity. The clinician should query patient educational status and estimate expected level of health literacy. The potential for family support should be evaluated by observing whether the patient is accompanied by a family member to the clinic. Documentation of key insights and risk factors from this initial evaluation helps to maintain continuity of care.

During the course of treatment, the extent of physician empathy has been established as a significant predictor in prevention of adverse health outcomes among diabetic patients. ${ }^{[48]}$ It is important for professional diabetic health-care providers to avoid assigning blame upon patients on failure of adherence and instead explore underlying sociocultural factors which may override patient's “individual" choices. Patients with limited health literacy should be explained instructions at a slow pace and with a controlled vocabulary with which the patient is familiar, and they should be encouraged to ask questions to clarify their doubts. ${ }^{[49]}$ Among women with diabetes, health-care providers should make concerted efforts to gain familial support for their patients through dedicated health communication. ${ }^{[44]}$

Recommended dietary choices should be culturally appropriate and economically affordable for the patient and must be accompanied with several healthy alternatives while planning their meals. If familial support is available, the health-care provider should take the opportunity to educate them regarding healthy diabetic diets and sensitize them regarding prioritizing it even if at variance with their own dietary preferences for the sake of their patient's health.
Poor adherence to regular exercise recommendations is a major barrier to attainment of desired health outcomes in diabetic patients. The health-care provider should be aware of certain environmental factors such as unsafe crime-infested neighborhoods or sociocultural resistance which prevents women from venturing out in public. The lack of sufficient open recreational spaces such as public parks also precludes opportunities for walking or exercise. ${ }^{[50]}$ The detection of such barriers which are mostly nonmodifiable in the short term should lead to promotion of alternative methods for increasing physical activity within the patient's homes.

\section{HEALTH POLICY APPROACHES IN ADDRESSING SOCIAL DETERMINANTS OF DIABETES MELLITUS IN THE INDIAN CONTEXT}

Health policy approaches for control of diabetes focus on provision of medications to diabetics through government health facilities but fail to assure follow-up and continuity of care. The onus of maintaining adherence to medications among diabetics has been deemed as entirely a function of the patients. There is no system check for follow-up of patients who default on their clinic appointments or encounter forced disruption of their medication due to lack of availability of any of the recommended drugs at the health facility. Similarly, minimum standards of blood glucose monitoring and other relevant investigations (such as $\mathrm{HbA1c}$, kidney function tests (KFT), and retinal screening) should be facilitated and followed at the level of the health system.

The national program for noncommunicable diseases including diabetes should include the strategy for community mobilization through health workers for sensitization of the family members and society to overcome regressive attitudes which threaten adherence to management and health outcomes in diabetic patients, especially women.

To overcome the challenge of poor knowledge of diabetes and reduced patient self-efficacy, the application of $\mathrm{m}$-Health technology may prove useful for provision of health education. Government health facilities with limited staff attending to very high patient load reduce opportunities for imparting regular health education, a problem which can be overcome by an evidence-based application of $\mathrm{m}$-Health technology. ${ }^{[51]}$ Furthermore, there is a need to operationalize electronic registration and systematic follow-up in case of missed appointments of diabetic patients with adverse social determinants who are at risk of poor medication adherence. A minimum level of health insurance for informal health 
workers earning daily wages to compensate them for lost earnings should be implemented to minimize missed appointments and sustain their medication adherence. The long-term gains accrued through reduction of the enormous costs ${ }^{[52]}$ for managing potential diabetic complications by promotion of medical adherence in such disadvantaged populations should guide health policy considerations while allocation of our limited health-care resources.

\section{Financial support and sponsorship}

Nil.

\section{Conflicts of interest}

There are no conflicts of interest.

\section{REFERENCES}

1. International Diabetes Federation. IDF Diabetes Atlas. $7^{\text {th }}$ ed. Brussels: International Diabetes Federation; 2015.

2. Fowler MJ. Microvascular and macrovascular complications of diabetes. Clin Diabetes 2008;26:77-82.

3. Verma K, Dadarwal M. Diabetes and quality of life: A theoretical perspective. J Soc Health Diabetes 2017;5:5-8.

4. Mannucci E, Dicembrini I, Lauria A, Pozzilli P. Is glucose control important for prevention of cardiovascular disease in diabetes? Diabetes Care 2013;36 Suppl 2:S259-63.

5. Skyler JS. Effects of glycemic control on diabetes complications and on the prevention, of diabetes. Clin Diabetes 2004;22:162-6.

6. Rhee MK, Slocum W, Ziemer DC, Culler SD, Cook CB, El-Kebbi IM, et al. Patient adherence improves glycemic control. Diabetes Educ 2005;31:240-50.

7. AADE. AADE7 self-care behaviors. Diabetes Educ 2008;34:445-9.

8. Dauchet L, Amouyel P, Hercberg S, Dallongeville J. Fruit and vegetable consumption and risk of coronary heart disease: A meta-analysis of cohort studies. J Nutr 2006;136:2588-93.

9. Duncan GE. Exercise, fitness, and cardiovascular disease risk in type 2 diabetes and the metabolic syndrome. Curr Diab Rep 2006;6:29-35.

10. Jack L Jr., Liburd L, Spencer T, Airhihenbuwa CO. Understanding the environmental issues in diabetes self-management education research: A reexamination of 8 studies in community-based settings. Ann Intern Med 2004;140:964-71.

11. Hill J, Nielsen M, Fox MH. Understanding the social factors that contribute to diabetes: A means to informing health care and social policies for the chronically ill. Perm J 2013;17:67-72.

12. Saydah S, Lochner K. Socioeconomic status and risk of diabetes-related mortality in the U.S. Public Health Rep 2010;125:377-88.

13. Brown AF, Ettner SL, Piette J, Weinberger M, Gregg E, Shapiro MF, et al. Socioeconomic position and health among persons with diabetes mellitus: A conceptual framework and review of the literature. Epidemiol Rev 2004;26:63-77.

14. Wilkinson R, Marmot M, editors. Social Determinants of Health: The Solid Facts. $2^{\text {nd }}$ ed. Copenhagen, Denmark: World Health Organization; 2003. [Monograph on the Internet]. Available from: http://www.euro. who.int/document/e81384.pdf. [Last cited on 2013 Jan 18].

15. Raphael D, Anstice S, Raine K, McGannon KR, Rizvi SK, Yu V. The social determinants of the incidence and management of type 2 diabetes mellitus: Are we prepared to rethink our questions and redirect our research activities? Leadersh Health Serv 2003;16:10-20.

16. Agardh E, Allebeck P, Hallqvist J, Moradi T, Sidorchuk A. Type 2 diabetes incidence and socio-economic position: A systematic review and meta-analysis. Int J Epidemiol 2011;40:804-18.
17. Walker RJ, Gebregziabher M, Martin-Harris B, Egede LE. Independent effects of socioeconomic and psychological social determinants of health on self-care and outcomes in type 2 diabetes. Gen Hosp Psychiatry 2014;36:662-8.

18. Walker RJ, Smalls BL, Campbell JA, Strom Williams JL, Egede LE. Impact of social determinants of health on outcomes for type 2 diabetes: A systematic review. Endocrine 2014;47:29-48.

19. Sabatâe E. Adherence to Long-term Therapies: Evidence for Action. $1^{\text {st }}$ ed. Geneva: World Health Organization; 2003.

20. Cramer JA. A systematic review of adherence with medications for diabetes. Diabetes Care 2004;27:1218-24.

21. Sankar UV, Lipska K, Mini GK, Sarma PS, Thankappan KR. The adherence to medications in diabetic patients in rural Kerala, India. Asia Pac J Public Health 2015;27:NP513-23.

22. Basu S, Khobragade M, Kumar A, Raut DK. Medical adherence and its predictors in Diabetes Mellitus patients attending government hospitals in the Indian Capital, Delhi, 2013: A cross sectional study. Int J Diabetes Dev Ctries 2015;35 Suppl 2:95.

23. Mukherjee S, Sharmasarkar B, Das KK, Bhattacharyya A, Deb A. Compliance to anti-diabetic drugs: Observations from the diabetic clinic of a medical college in Kolkata, India. J Clin Diagn Res 2013;7:661-5.

24. World Health Organization. Global Health Expenditure Database. Total Health Expenditure (THE) \% Gross Domestic Product (GDP); 2012. Available from: http://www.apps.who.int/nha/database/Select/ Indicators/en. [Last accessed on 2017 Jan 01].

25. La Forgia G, Nagpal S. Government-Sponsored Health Insurance in India: Are You Covered? Washington DC: World Bank Publications; 2012.

26. Yesudian CA, Grepstad M, Visintin E, Ferrario A. The economic burden of diabetes in India: A review of the literature. Global Health 2014;10:80.

27. Iglay K, Hannachi H, Joseph Howie P, Xu J, Li X, Engel SS, et al. Prevalence and co-prevalence of comorbidities among patients with type 2 diabetes mellitus. Curr Med Res Opin 2016;32:1243-52.

28. Schabert J, Browne JL, Mosely K, Speight J. Social stigma in diabetes: A framework to understand a growing problem for an increasing epidemic. Patient 2013;6:1-10.

29. Mayberry LS, Osborn CY. Family support, medication adherence, and glycemic control among adults with type 2 diabetes. Diabetes Care 2012;35:1239-45.

30. Gulabani M, John M, Isaac R. Knowledge of diabetes, its treatment and complications amongst diabetic patients in a tertiary care hospital. Indian J Community Med 2008;33:204-6.

31. Shah VN, Kamdar PK, Shah N. Assessing the knowledge, attitudes and practice of type 2 diabetes among patients of Saurashtra region, Gujarat. Int J Diabetes Dev Ctries 2009;29:118-22.

32. Wallston KA, Rothman RL, Cherrington A. Psychometric properties of the perceived diabetes self-management scale (PDSMS). J Behav Med 2007;30:395-401.

33. Heisler M, Piette JD, Spencer M, Kieffer E, Vijan S. The relationship between knowledge of recent HbA1c values and diabetes care understanding and self-management. Diabetes Care 2005;28:816-22.

34. Cavanaugh KL. Health literacy in diabetes care: Explanation, evidence and equipment. Diabetes Manag (Lond) 2011;1:191-9.

35. Institute of Medicine, editor. Health Literacy: A Prescription to End Confusion. Washington, DC: National Academies Press; 2004.

36. Sarkar U, Karter AJ, Liu JY, Moffet HH, Adler NE, Schillinger D. Hypoglycemia is more common among type 2 diabetes patients with limited health literacy: The Diabetes Study of Northern California (DISTANCE). J Gen Intern Med 2010;25:962-8.

37. Health literacy: Report of the Council on Scientific Affairs. Ad Hoc Committee on Health Literacy for the Council on Scientific Affairs, American Medical Association. JAMA 1999;281:552-7.

38. Odegard PS, Gray SL. Barriers to medication adherence in poorly controlled diabetes mellitus. Diabetes Educ 2008;34:692-7. 
39. Holler HJ. Understanding the use of the exchange lists for meal planning in diabetes management. Diabetes Educ 1991;17:474-84.

40. Barnard KD, Holt RI. The aims of diabetes care. In: Holt RI, Cockram CS, Flyvberg A, Goldstein BJ, editors. Comprehensive Textbook of Diabetes. Chichester, West Sussex, UK; Hoboken, NJ: Wiley Blackwell; 2016. p. 314-25.

41. Rosland AM, Kieffer E, Israel B, Cofield M, Palmisano G, Sinco B, et al. When is social support important? The association of family support and professional support with specific diabetes self-management behaviors. J Gen Intern Med 2008;23:1992-9.

42. Osborn CY, Egede LE. The relationship between depressive symptoms and medication nonadherence in type 2 diabetes: The role of social support. Gen Hosp Psychiatry 2012;34:249-53.

43. Sacco WP, Yanover T. Diabetes and depression: The role of social support and medical symptoms. J Behav Med 2006;29:523-31.

44. Bajaj S, Jawad F, Islam N, Mahtab H, Bhattarai J, Shrestha D, et al. South Asian women with diabetes: Psychosocial challenges and management: Consensus statement. Indian J Endocrinol Metab 2013;17:548-62.

45. Cohen DA, McKenzie TL, Sehgal A, Williamson S, Golinelli D, Lurie N. Contribution of public parks to physical activity. Am J Public Health 2007;97:509-14.

46. Diez Roux AV, Evenson KR, McGinn AP, Brown DG, Moore L,
Brines S, et al. Availability of recreational resources and physical activity in adults. Am J Public Health 2007;97:493-9.

47. Syed ST, Gerber BS, Sharp LK. Traveling towards disease: Transportation barriers to health care access. J Community Health 2013;38:976-93.

48. Del Canale S, Louis DZ, Maio V, Wang X, Rossi G, Hojat M, et al. The relationship between physician empathy and disease complications: An empirical study of primary care physicians and their diabetic patients in Parma, Italy. Acad Med 2012;87:1243-9.

49. Patrick TB, Monga HK, Sievert ME, Houston Hall J, Longo DR. Evaluation of controlled vocabulary resources for development of a consumer entry vocabulary for diabetes. J Med Internet Res 2001;3:E24.

50. Booth GL, Creatore MI, Moineddin R, Gozdyra P, Weyman JT, Matheson FI, et al. Unwalkable neighborhoods, poverty, and the risk of diabetes among recent immigrants to Canada compared with long-term residents. Diabetes Care 2013;36:302-8.

51. Hamine S, Gerth-Guyette E, Faulx D, Green BB, Ginsburg AS. Impact of mHealth chronic disease management on treatment adherence and patient outcomes: A systematic review. J Med Internet Res 2015;17:e52.

52. Seuring T, Archangelidi O, Suhrcke M. The economic costs of type 2 diabetes: A global systematic review. Pharmacoeconomics 2015;33:811-31. 